\title{
The mechanism of hydrogen donation by bio-acids over metal supported on nitrogen-doped carbon nanotubes
}

\author{
Jiajun Zhang ${ }^{\mathrm{a}, \mathrm{b}}$, Xiaolei Zhang ${ }^{\mathrm{a}, *}$, Amin Osatiashtiani ${ }^{\mathrm{c}}$, Kai Hong Luo ${ }^{\mathrm{d}}$, Dekui Shen ${ }^{\mathrm{e}}, \mathrm{Jun} \mathrm{Li}^{\mathrm{a}}$, \\ Anthony Bridgwater ${ }^{c}$ \\ ${ }^{a}$ Department of Chemical and Process Engineering, University of Strathclyde, Glasgow, United Kingdom \\ ${ }^{\mathrm{b}}$ Center for Combustion Energy, Key Laboratory for Thermal Science and Power Engineering of Ministry of Education, Department of Energy and Power Engineering, \\ Tsinghua University, Beijing 100084, China \\ ${ }^{\mathrm{c}}$ Energy \& Bioproducts Research Institute (EBRI), School of Engineering and Applied Science, Aston University, Aston Triangle, Birmingham, B4 7ET, United Kingdom \\ ${ }^{\mathrm{d}}$ Department of Mechanical Engineering, University College London, Torrington Place, London, WC1E 7JE, UK \\ ${ }^{\mathrm{e}}$ Key Laboratory of Energy Thermal Conversion and Control of Ministry of Education, Southeast University, Nanjing, China
}

\section{A R T I C L E I N F O}

\section{Keywords:}

Acetic acid

Formic acid

Carbon nanotubes

Molybdenum

Biomass

\begin{abstract}
A B S T R A C T
Biomass-derived carboxylic acids (e.g. acetic acid AcOH and formic acid FA) are a green and low-cost hydrogen source to replace hazardous $\mathrm{H}_{2}$ gas in in-situ hydrogenation processes. To date, bio-acids dehydrogenation has been mainly conducted using noble metal catalysts which would negatively impact the process economy, thus development of efficient non-noble metal catalysts for this purpose is highly desirable. In this study, the performance of transition metals supported on nitrogen doped carbon nanotubes was thoroughly evaluated by computational modelling based on Density Functional Theory (DFT). Results revealed that, out of the 10 selected transition metal candidates, molybdenum (Mo) was most active for binding AcOH and a combination of Mo and nitrogen doping significantly enhanced binding to the carboxylic acid molecules compared to pristine carbon nanotubes (CNTs). The newly designed Mo/N-CNT catalysts considerably facilitated the bio-acids decomposition compared to the non-catalytic scenarios by lowering energy barriers. FA distinctly outperformed AcOH in hydrogen donation over Mo/N-CNT catalysts, through its spontaneous cleavage leading to facile hydrogen donation.
\end{abstract}

\section{Introduction}

The rapid economic growth and increase in the global population have accelerated the consumption of fossil resources. This has resulted in an unprecedented increase in the level of $\mathrm{CO}_{2}$ and other greenhouse gases (GHG) emissions, threatening the future of our planet by contributing to global warming [1]. Therefore, alternative sustainable feedstocks are needed to meet the demands for organic chemicals and fuels.

Non-edible and waste biomass such as lignocellulose and triglycerides are considered a sustainable source of carbon that can be used to produce green and low-cost chemicals and fuels. However, lignocellulosic biomass has high oxygen content, thus itself or its derivative has to undergo some deoxygenation steps to be converted to the desired products [2]. Conventionally, deoxygenation is conducted via hydrogenation using precious metal-based catalysts and molecular $\mathrm{H}_{2}$.
However, this approach can have negative impact on process economy and safety, owing to the high cost of precious metals (e. g. Pt, Pd, and $\mathrm{Ru}$ ) and the need for high $\mathrm{H}_{2}$ pressure ( $>30$ bar) [3]. Therefore, alternative sustainable hydrogen sources, as well as the efficient catalysts to maximise the energy efficiency of the hydrogen transfer process are sought after.

Various alternative organic hydrogen donors have been reviewed in detail in our previous work [4]. Among them, bio-acids are promising, not only as hydrogen donors, but also as potential chemicals for hydrogen storage [5]. The research on bio-acids decomposition for in-situ hydrogen generation has been focused mainly on acetic acid (AcOH) and formic acid (FA) [6-8], because they are abundant in bio-oil and more readily decomposed compared to other bio-based carboxylic acids $[9,10]$. Jiang et al. [6] predicted the pathway of FA decomposition over $\mathrm{Cu}(111)$ as $\mathrm{HCOOH} \rightarrow \mathrm{HCO}+\mathrm{OH} \rightarrow \mathrm{H}+\mathrm{CO}+\mathrm{OH}$. Li et al. [11] reported the decomposition mechanism of $\mathrm{AcOH}$ over $\mathrm{Co}$ (111) stepped

\footnotetext{
* Corresponding author.

E-mail address: xiaolei.zhang@strath.ac.uk (X. Zhang).
} 
surface, suggesting that the reaction pathway follows $\mathrm{CH}_{3} \mathrm{COOH} \rightarrow$ $\mathrm{CH}_{3} \mathrm{CO}+\mathrm{OH} \rightarrow \mathrm{CH}_{2} \mathrm{CO}+\mathrm{H}+\mathrm{OH} \rightarrow \mathrm{CH}_{2}+\mathrm{CO}+\mathrm{H}+\mathrm{OH} \rightarrow \mathrm{CH}+\mathrm{CO}+2 \mathrm{H}$ $+\mathrm{OH}$. There are other different reaction mechanisms over noble metals, producing $\mathrm{CH}_{4}$ and $\mathrm{CO}$ from $\mathrm{AcOH}$ decomposition, and $\mathrm{CO}_{2}$ and $\mathrm{H}_{2}$ from FA decomposition, respectively $[7,12,13]$. Also, our previous DFT study demonstrated that Mo (110) exhibited a great potential as a catalyst for the dehydrogenation of $\mathrm{FA}$ and $\mathrm{AcOH}$, due to their exothermic property and lower energy barriers during the decomposition [4]. Nevertheless, unsupported metal catalysts are rarely used in practice because metal clusters are usually needed to be evenly dispersed on a high surface area support to maximise the interface between the reactants and the catalytic sites. Furthermore, the interaction between the support and the metal can have significant impact on the activity and selectivity of the catalytic system, therefore selection of an appropriate support and understanding the metal-support interactions are crucial to the smart catalyst design [14].

Several studies have reported the decomposition of bio-acids over heterogeneous catalysts with a variety of supports including metal oxides [15,16], zeolites [17], as well as carbon based materials [18,19]. Among the various types of supports, carbon nanotubes (CNTs) are very interesting materials, owing to their excellent thermal stability (up to $3000 \mathrm{~K}$ ), carbonaceous deposit resistance, as well as large specific surface area (over $1000 \mathrm{~m}^{2} / \mathrm{g}$ ) which allow a higher metal dispersion compared to other supports [20,21]. Additionally, CNTs can be prepared using residual biomass, contributing to the reduction in carbon footprint [22-24]. CNTs functionalised with transition metals [25], defects and heteroatoms $[26,27]$ have demonstrated to be promising catalysts for redox reactions by achieving high conversion rates and selectivity to the desired products [28]. For example, N-doped CNTs have shown remarkable activities in redox reaction by tailoring the local electron property [29]. Metal doped CNTs have also shown promising results in the hydrodeoxygenation of anisole [30], Aerobic oxidation of 5-hydroxymethylfurfural to 2,5-furandicarboxylic acid [31], and transformation of furfural to cyclopentanone, as well as in-situ hydrogen generation via decomposition of bio-acids [32]. Ding et al. [33] reported the decomposition of FA into $\mathrm{CO}_{2}$ and $\mathrm{H}_{2}$ over Pd/CNTs at room temperature with a high turnover frequency (TOF) of $1135 \mathrm{~h}^{-1}$. Nabid and co-workers [34] synthesized Ag core Pd shell nanoparticles supported on CNTs without any additives and achieved FA dehydrogenation with an overall activation energy of $28.28 \mathrm{KJ} \mathrm{mol}^{-1}$. Bi et al. [35] modified CNTs by $\mathrm{N}$ doping, achieving TOF $>5000 \mathrm{~h}^{-1}$ and near complete conversion of FA.

In a N-CNT support, four types of nitrogen atoms could be present (as illustrated in Fig. 1); 1) graphitic $\mathrm{N}\left(\mathrm{N}_{\mathrm{g}}\right.$-CNTs), 2) (vacancy) pyridinic $\mathrm{N}$ (referred as pyridinic nitrogen in this work, $\mathrm{N}_{\mathrm{p}}$-CNTs), 3) pyrrolic $\mathrm{N}$, and 4) pyridinic $\mathrm{N}-\mathrm{O}$. Previous investigations into $\mathrm{N}$-CNTs indicate that $\mathrm{N}_{\mathrm{g}}$ CNTs and $\mathrm{N}_{\mathrm{p}}$-CNTs are the most common types of $\mathrm{N}$ dopants in CNTs $[36,37]$. Pyridinic $\mathrm{N}$ atoms $\left(\mathrm{N}_{\mathrm{p}}\right)$ are normally located at the edges or in the vacancy of the CNT surface and are bonded to two carbon atoms, and

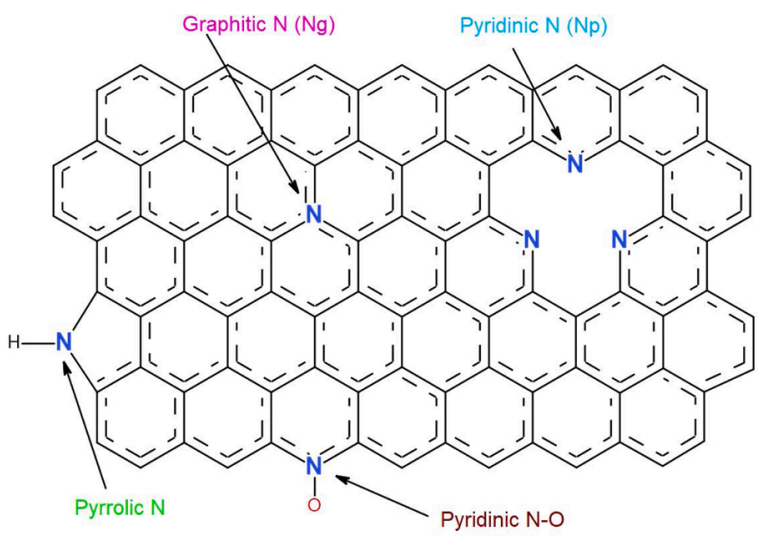

Fig. 1. Common types of $\mathrm{N}$ doping in carbon matrices $[37,43]$. the three sp2 orbitals are occupied by four electrons, where two electrons are used to form two $\delta$ bonds with carbon atoms, and the other two hybridized electrons form a lone pair. The remaining electron in $\mathrm{N}_{\mathrm{p}}$ joins the adjacent carbon atoms to form a $\pi$ bond. The lone electron pair would endow the $\mathrm{N}_{\mathrm{p}}$-CNTs with Lewis basicity, while the $\pi$ electron acts as an electron acceptor [38-40]. $\mathrm{N}_{\mathrm{g}}$ has similar sp2 hybridisation as $\mathrm{N}_{\mathrm{p}}$; four orbitals are occupied by only four electrons to form three $\delta$ bonds and one $\pi$, and the fifth electron is not accommodated in a bonding orbital, because it is in a higher energy state and delocalised from the $\mathrm{N}$ site, functioning as an electron donor [29,41,42].

Due to the different basicity and acidity, each of the various doping types of $\mathrm{N}$ in CNTs promotes different catalytic reactions $[44,45]$. Although experimental data suggest that functionalised CNTs are promising catalysts for in-situ hydrogen generation from the decomposition of bio-acids [33-35], the literature on the reaction mechanism is very limited. Particularly, the interactions between each functional component of the CNTs catalyst composite have rarely been explored.

In this study, the catalytic decomposition of $\mathrm{AcOH}$ and FA for hydrogen production over the metal supported on N-CNTs was investigated with a focus on the cleavage of hydrogen related bonds. Ten transition metals including Ni, Mo, Fe, Co, Pt, Rh, Ru, $\mathrm{Zn}, \mathrm{Cu}$, and Pd, as well as six types of CNT-based catalyst supports (5 functionalised CNT and the pristine $\mathrm{CNT}$ ) were compared with respect to their binding energy in adsorbing $\mathrm{AcOH}$. AcOH and FA were then evaluated in terms of their adsorption process and reactivity in dehydrogenation over the Metal/N-CNT catalysts, and the cleavage of the corresponding bonds was tracked throughout the decomposition reaction.

\section{Methodology}

The first-principle density functional theory with dispersion correction (DFT-D) calculations was implemented in CASTEP, and models were established in Materials Studio 2017 R2 from BIOVIA [46,47]. The generalised gradient corrected approximation (GGA) [48] treated by the Perdew-Burke-Ernzerhof (PBE) exchange-correlation potential with long-range dispersion correction via Grimme's scheme was used to calculate the exchange-correlation energy [49]. The on-the-fly generated (OTFG) ultra-soft pseudopotential was employed as the scheme in the representation of reciprocal space for all the elements [50,51]. The plane-wave cut-off energy was set to $600 \mathrm{eV}$ for all the calculations based on its independence test (Fig. S1a). The Brillouin zone was sampled using a $2 \times 1 \times 4$ Monkhorst-Pack k-point (spacing of $0.03 \AA^{-1}$ ) with a smearing of $0.1 \mathrm{eV}$, based on its independence test (Fig. S1b). The self-consistent field (SCF) tolerance was set to $10^{-6} \mathrm{eV} /$ atom. The entire calculation was performed with a convergence threshold of $10^{-5}$ $\mathrm{eV} /$ atom on energy, $0.03 \mathrm{eV} / \AA$ on maximum force, and $10^{-3} \AA$ on the maximum displacement. No symmetry constraint was used for any modelling.

All the models were based on a two-unit supercell of achiral zigzag (n $=12, \mathrm{~m}=0, \Theta=0^{\circ}$ ) form single wall CNT (SWCNT) with a diameter of $9.5 \AA$. A $15 \AA$ vacuum region was created above the top of the CNT. Based on the tests with larger supercell models, the size of CNT model used in this study would be adequate to get reliable computation results (Fig. S2). Geometry optimisation was implemented to every model before energy was calculated. The transition state (TS) was completely determined by the LST/QST method, and the TSs for the dominant reaction steps were confirmed by the unique imaginary frequency (Table S2). Hirshfeld charge was calculated for atomic electron analysis. The adsorption energy $\left(E_{a d}\right)$ was determined by Eq. 1, where $E_{\text {catalyst }}$, $E_{\text {adsorbate }}$ and $E_{\text {adsorbate/catalyst }}$ are the total energies of clean catalyst, free adsorbate molecule and catalyst with adsorbed molecule, respectively. The energy barriers of reactions ( $E_{\text {barrier }}$ ) were determined by the difference between the energies of transition state and reactant, as shown in Eq. 2, where $E_{\text {transition state }}$ and $E_{\text {reactant }}$ are the total energies of the transition state and reactant of a reaction, respectively. 
$\mathrm{E}_{\mathrm{ad}}=\mathrm{E}_{\text {adsorbate/catalyst }}-\left(\mathrm{E}_{\text {catalyst }}+\mathrm{E}_{\text {adsorbate }}\right)$

$\mathrm{E}_{\text {barrier }}=\mathrm{E}_{\text {transition state }}-\mathrm{E}_{\text {reactant }}$

The bond dissociation energies (BDEs) were determined by Eq. 3, where $E_{\text {molecule }}$ is the molecule energy, and $E_{\text {fragments }}$ is the energy summation of each decomposed fragments from bond cleavage.

$\mathrm{BDE}=\mathrm{E}_{\text {molecule }}-\mathrm{E}_{\text {fragments }}$

The electron density difference (EDD) was determined by Eq. 4, where $\rho_{\text {adsorbate@cata }}$ is the electron density of the whole system of adsorbate and catalyst, and $\rho_{\text {adsorbate }}$ and $\rho_{\text {cata }}$ are the unperturbed electron densities of the adsorbate and the catalyst structure, respectively.

$\Delta \rho=\rho_{\text {adsorbate } @ \text { cata }}-\left(\rho_{\text {adsorbate }}+\rho_{\text {cata }}\right)$

\section{Results and discussion}

\subsection{Impact of metal and nitrogen type on acetic acid adsorption energy}

To evaluate the performance of various transition metals and N-CNT catalyst supports, the adsorption energy of $\mathrm{AcOH}$ on $10 \mathrm{~N}_{\mathrm{p}} \mathrm{CNT}$ supported transition metals as well as the corresponding unsupported metals were compared, as shown in Figs. 2 and S3. The results reveal that the adsorption energy of $\mathrm{AcOH}$ on the supported metals is generally larger than that of the unsupported metal facets [4], indicating the enhanced interactions between $\mathrm{AcOH}$ and the CNT supported catalysts. Among the selected materials, Mo and Pt supported on $\mathrm{N}_{\mathrm{p}}$-CNT exhibited the strongest AcOH binding energy $(1.76 \mathrm{eV})$, implying that they are probably more catalytically active than other transition metals selected in activating carboxylic acids. Since precious metal catalysts were avoided in this study, Mo was selected for further investigation.

The structure of the aforementioned two common types of N-CNT models $\left(\mathrm{N}_{\mathrm{p}}-\mathrm{CNT}\right.$ and $\mathrm{N}_{\mathrm{g}}-\mathrm{CNT}$ ) supported Mo catalysts was established and demonstrated in Fig. 3, along with the pristine CNT model. The impact of different $\mathrm{N}$ chemical environments on the adsorption energy of AcOH on the metal-doped and metal-free CNT was compared, and the results are summarised in Table 1.

Results showed that the pristine CNT as the catalyst led to the lowest adsorption energy (close to physical adsorption, distance larger than 3
$\AA$ ) of AcOH. N-CNTs gave rise to slightly larger adsorption energy, however, no obvious difference was observed between $\mathrm{N}_{\mathrm{p}}$ and $\mathrm{N}_{\mathrm{g}}$ types; the distances between the molecule and catalysts for the above cases were all larger than $2.7 \AA$ (Fig. S4). The modelling results reveal that the adsorption energy of AcOH significantly increased when Mo was present on the CNT surface, with simultaneous shorter distances (around $2 \AA$ ) between the molecule and catalysts, confirming the binding promotion effect of $\mathrm{Mo}$ on the $\mathrm{AcOH}$ adsorption, in agreement with the literature [4]. Over Mo/ $\mathrm{N}_{\mathrm{p}}-\mathrm{CNT}$, AcOH exhibited the highest binding energy $(-1.76 \mathrm{eV})$ than that of $\mathrm{Mo} / \mathrm{N}_{\mathrm{g}}-\mathrm{CNT}$ and $\mathrm{Mo} / \mathrm{CNT}$, ascribed to the unpaired electron of pyridinic $\mathrm{N}$ which acts as electron acceptor (Lewis acid), reinforcing the binding between the catalyst and the adsorbate molecule [52]. This also explains the slightly lower adsorption energy of $\mathrm{AcOH}$ over Mo/CNT. Compared to $\mathrm{Mo} / \mathrm{N}_{\mathrm{p}}-\mathrm{CNT}$ and $\mathrm{Mo} / \mathrm{CNT}$, the adsorption energy was obviously decreased by $\mathrm{Mo} / \mathrm{N}_{\mathrm{g}}$-CNT, indicating the weaker binding between the $\mathrm{AcOH}$ molecule and $\mathrm{Mo} / \mathrm{N}_{\mathrm{g}}-\mathrm{CNT}$, resulting from the aforementioned delocalized electron of $\mathrm{N}_{\mathrm{g}}$ [29]. It is also found that $\mathrm{N}_{\mathrm{p}}$-CNT and $\mathrm{N}_{\mathrm{g}}$-CNT exhibit different acid and base effects on $\mathrm{AcOH}$ adsorption only in the presence of Mo, which can be attributed to the synergistic effects between $\mathrm{N}$ and Mo atoms, in line with the reported results in the literature [40,53]. This difference in terms of acid and base effects may also endow the catalysts with different redox properties. It is thus hypothesised that the two types of $\mathrm{N}$ doping would lead to different catalytic performance of Mo/N-CNTs in the decomposition of bio-acids. Besides the adsorption performance, the stability of these two catalysts were tested (Fig. S5). Results show that $\mathrm{Mo} / \mathrm{N}_{\mathrm{p}}$-CNT had higher thermal stability, and thus could operate in high temperatures up to $1000 \mathrm{~K}$ with little distortion, whereas $\mathrm{Mo} / \mathrm{N}_{\mathrm{g}}-\mathrm{CNT}$ is suitable for low temperature operation scenarios.

\subsection{Dehydrogenation of acetic acid over Mo/N-CNTs}

Different adsorption energies of $\mathrm{AcOH}$ in various configurations (Table S1) over the two types of catalysts of Mo/ $\mathrm{N}_{\mathrm{p}}-\mathrm{CNT}$ and $\mathrm{Mo} / \mathrm{N}_{\mathrm{g}}-$ CNT are compared in Table 2. The bond dissociation energies (BDEs) of each bond in free molecule are shown in Fig. 4 for comparison. In both cases, $\mathrm{AcOH}$ bonded onto Mo by chemical adsorption through $\mathrm{C}_{\beta}$-Mo, $\mathrm{O}_{\alpha}-\mathrm{Mo}$, and $\mathrm{O}_{\beta}$-Mo, and by weaker binding through $\mathrm{C}_{\alpha}-\mathrm{Mo}$, where Mo/ $\mathrm{N}_{\mathrm{p}}$-CNT resulted in higher binding energy than $\mathrm{Mo} / \mathrm{N}_{\mathrm{g}}$-CNT in all strong adsorption circumstances. Interestingly, dissociative adsorption was observed when $\mathrm{AcOH}$ bonded to the $\mathrm{Mo} / \mathrm{N}_{\mathrm{p}}-\mathrm{CNT}$ through $\mathrm{O}_{\beta}-\mathrm{Mo}$, where the molecule decomposed into hydroxyl and acetyl (with the $\mathrm{C}-\mathrm{O}$ bond distance of $2.7 \AA$ ) during the adsorption. The dissociative adsorption is

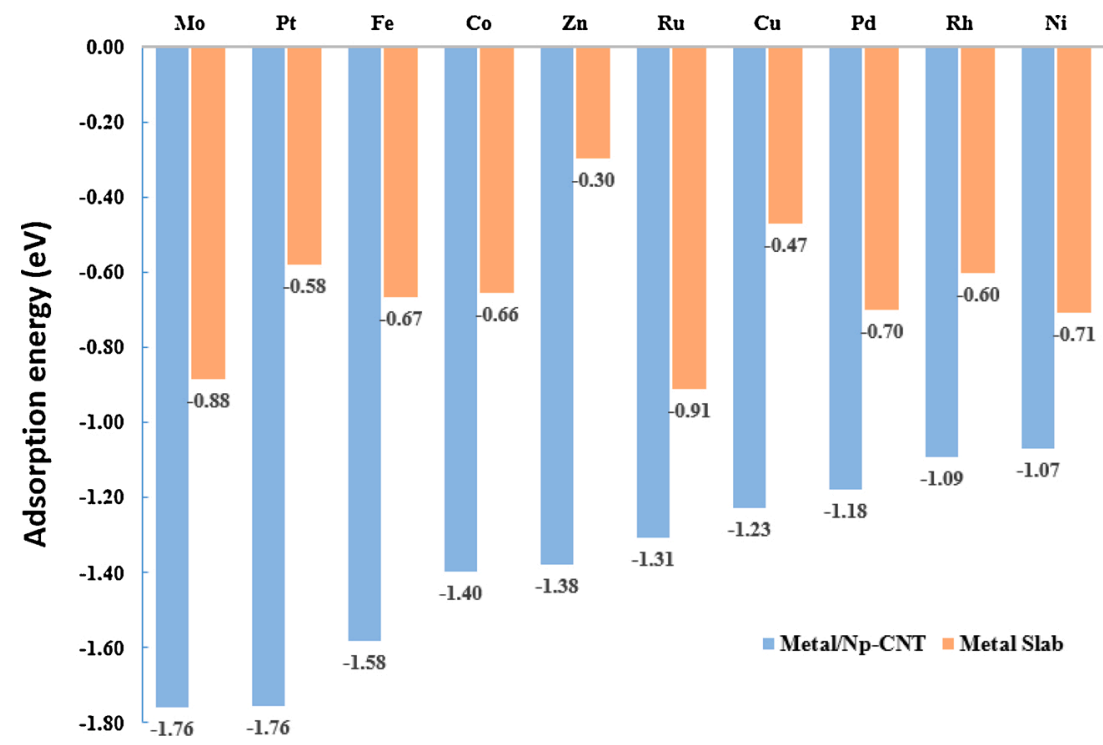

Fig. 2. Adsorption energy of acetic acid over metal/ $\mathrm{N}_{\mathrm{p}}$-CNTs (from this work) and pure metal facets (from our previous work [4]). 

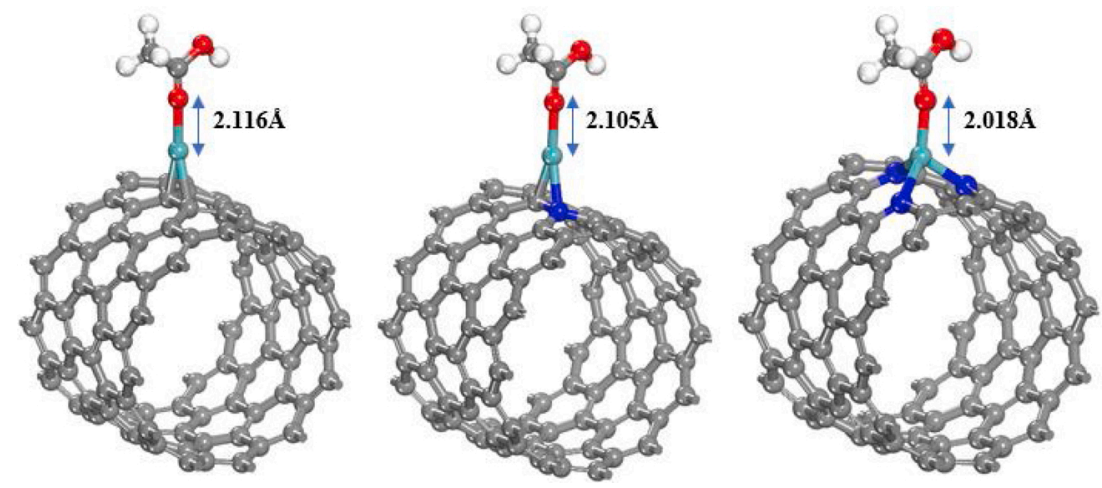

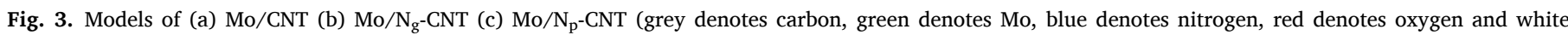
denotes hydrogen).

Table 1

Adsorption energy of AcOH on (functionalised) CNTs.

\begin{tabular}{|c|c|c|c|c|c|c|}
\hline $\begin{array}{l}\text { Active site } \\
\text { (catalyst) }\end{array}$ & $\begin{array}{l}\mathrm{Mo} / \mathrm{N}_{\mathrm{p}^{-}} \\
\mathrm{CNT}\end{array}$ & $\begin{array}{l}\mathrm{Mo} / \mathrm{N}_{\mathrm{g}^{-}} \\
\mathrm{CNT}\end{array}$ & $\begin{array}{l}\text { Mo/ } \\
\text { CNT }\end{array}$ & $\begin{array}{l}\mathrm{N}_{\mathrm{p}^{-}} \\
\mathrm{CNT}\end{array}$ & $\begin{array}{l}\mathrm{N}_{\mathrm{g}^{-}} \\
\mathrm{CNT}\end{array}$ & CNT \\
\hline $\begin{array}{c}\mathrm{E}_{\mathrm{ad}}(\mathrm{AcOH}) \\
(\mathrm{eV})\end{array}$ & -1.76 & -1.61 & -1.72 & -0.73 & $\begin{array}{l}-0.73 \\
*\end{array}$ & $\begin{array}{l}-0.63 \\
*\end{array}$ \\
\hline
\end{tabular}

* Only stable weak adsorption observed, and the corresponding configurations are shown in Fig. S4.

Table 2

Adsorption energy of $\mathrm{AcOH}$ on $\mathrm{Mo} / \mathrm{N}-\mathrm{CNT}$ with different configurations.

\begin{tabular}{lllll}
\hline $\mathrm{E}_{\mathrm{ad}}(\mathrm{AcOH})(\mathrm{eV})$ & $\mathrm{C}_{\alpha}-\mathrm{Mo}$ & $\mathrm{C}_{\beta}-\mathrm{Mo}$ & $\mathrm{O}_{\alpha}-\mathrm{Mo}$ & $\mathrm{O}_{\beta}-\mathrm{Mo}$ \\
\hline $\mathrm{Mo} / \mathrm{N}_{\mathrm{p}}-\mathrm{CNT}$ & $-0.58^{*}$ & -2.41 & -1.76 & -2.61 \\
$\mathrm{Mo} / \mathrm{N}_{\mathrm{g}}-\mathrm{CNT}$ & $-0.75^{*}$ & -1.99 & -1.61 & -2.11
\end{tabular}

* Only stable weak adsorption observed.

common for molecular hydrogen adsorption over transition metals [54], however the dissociative $\mathrm{AcOH}$ adsorption is observed for the first time. The dissociative adsorption of $\mathrm{AcOH}$ simultaneously led to the largest adsorption energy of $-2.61 \mathrm{eV}$ over $\mathrm{Mo} / \mathrm{N}_{\mathrm{p}}$-CNT through $\mathrm{O}_{\beta}-$ Mo bond. The same $\mathrm{O}_{\beta}$ - Mo bond also led to the largest adsorption energy of $-2.11 \mathrm{eV}$ when $\mathrm{AcOH}$ molecule adsorbed on $\mathrm{Mo} / \mathrm{N}_{\mathrm{g}}$-CNT. The difference between the adsorption energies of $\mathrm{AcOH}$ on Mo doped $\mathrm{N}_{\mathrm{g}}$ and $\mathrm{N}_{\mathrm{p}}$-CNT catalysts is associated with their electron donation and acceptation properties respectively, where $\mathrm{N}_{\mathrm{p}}$-CNT with higher acidity shows stronger binding to $\mathrm{AcOH}$.

The most favourable reaction pathways of $\mathrm{AcOH}$ decomposition over $\mathrm{Mo} / \mathrm{N}_{\mathrm{p}}$-CNT are shown in Fig. 5, which were determined based on the cleavage energy calculation for each bond inside the acid molecule, as well as inside the lower fragment structures (the lowest energy barrier values among all parallel bonds cleavage are shown, and the details for other parallel reactions are shown in Table S3). The modelling results predict that the decomposition of $\mathrm{AcOH}$ started with the dissociative adsorption, producing hydroxyl and acetyl fragments. Subsequently, acetyl cracked into $\mathrm{CO}$ and methyl fragments with a small energy barrier of $0.32 \mathrm{eV}$ and reaction energy of $-0.68 \mathrm{eV}$. Further decomposition of methyl released three $\mathrm{H}$ atoms in sequence with the energy barriers of $1.74 \mathrm{eV}, 1.47 \mathrm{eV}$ and $2.54 \mathrm{eV}$, respectively. Another $\mathrm{H}$ cleaved from the hydroxyl with an energy barrier of $2.03 \mathrm{eV}$. It is found that over $\mathrm{Mo} / \mathrm{N}_{\mathrm{p}}$ $\mathrm{CNT}$, the majority of elementary steps amid the favourable reaction pathway of $\mathrm{AcOH}$ decomposition are endothermic, except the thermodynamically favoured $\mathrm{C}-\mathrm{C}$ and initial $\mathrm{C}-\mathrm{O}$ cleavage.

AcOH did not show dissociative adsorption over Mo/ $\mathrm{N}_{\mathrm{g}}$-CNT (Fig. 6 and Table S1), instead the adsorbed structure underwent facile decomposition to produce acetyl and hydroxyl with a small energy barrier of $0.21 \mathrm{eV}$ (Table S3), with an exothermic reaction energy of $-0.77 \mathrm{eV}$. The

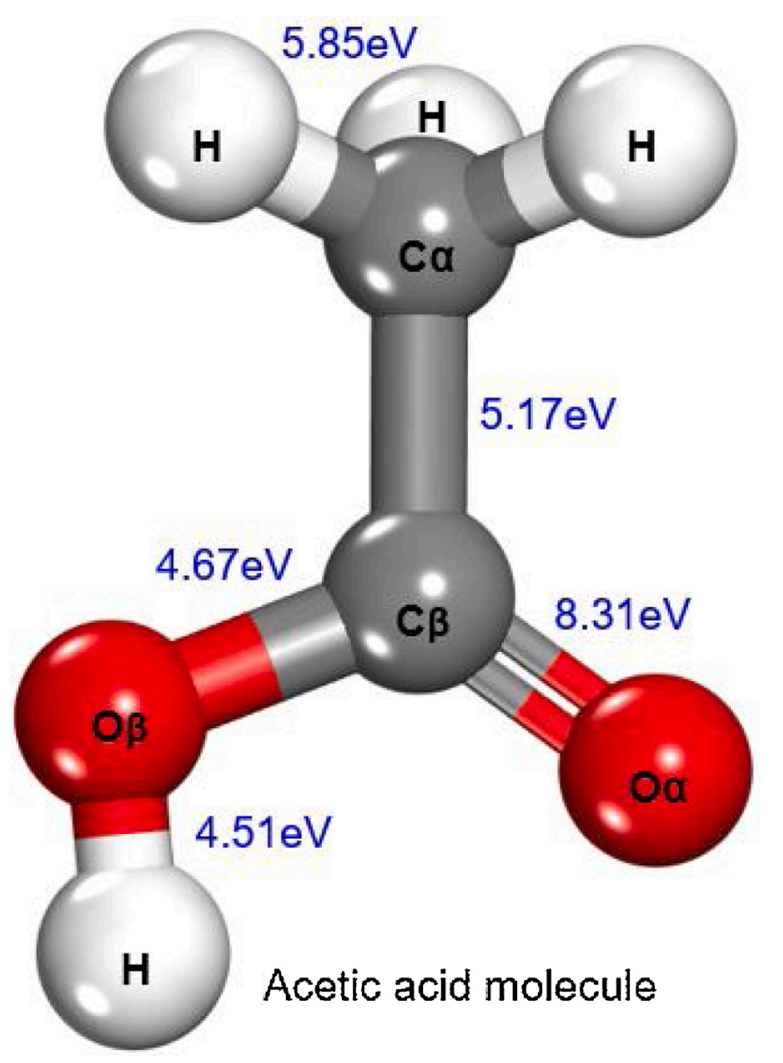

Fig. 4. Dissociation energy for each bond (blue font) in acetic acid free molecule [4].

modeling shows that the $\mathrm{C}-\mathrm{C}$ bond strength in the adsorbed acetyl group was reinforced over $\mathrm{Mo} / \mathrm{N}_{\mathrm{g}}-\mathrm{CNT}$, with a shorter bond length of $1.49 \AA$ compared to $1.53 \AA$ over Mo/ $\mathrm{N}_{\mathrm{p}}$-CNT and $1.51 \AA$ in free molecule status $[4,55]$, and this change would be analysed in detail in Section 3.4. As a result, the $\mathrm{C}=\mathrm{O}$ bond cleaved firstly, retaining the structure of $\mathrm{CH}_{3}-\mathrm{C}$. $\mathrm{CH}_{3}-\mathrm{C}$ would then decompose into methyl fragment and carbon atoms with a large energy barrier of $2.47 \mathrm{eV}$. The cleavage of $\mathrm{C}=\mathrm{O}$ prior to $\mathrm{C}-\mathrm{C}$ was also observed in the decomposition of $\mathrm{AcOH}$ over a Mo slab in our previous research [4]. The release of $\mathrm{H}$ atoms from methyl over $\mathrm{Mo} / \mathrm{N}_{\mathrm{g}}$-CNT had the energy barriers of $0.36 \mathrm{eV}, 0.72 \mathrm{eV}$ and $3.74 \mathrm{eV}$, respectively. Besides, the cleavage of hydroxyl over $\mathrm{Mo} / \mathrm{N}_{\mathrm{g}}$-CNT required additional energy of $1.58 \mathrm{eV}$. The cleaved $\mathrm{H}$ atoms from the decomposition process of acid molecules would stay on the metal temporarily before they continue to migrate or spill over in real hydrogenation circumstances [56]. 


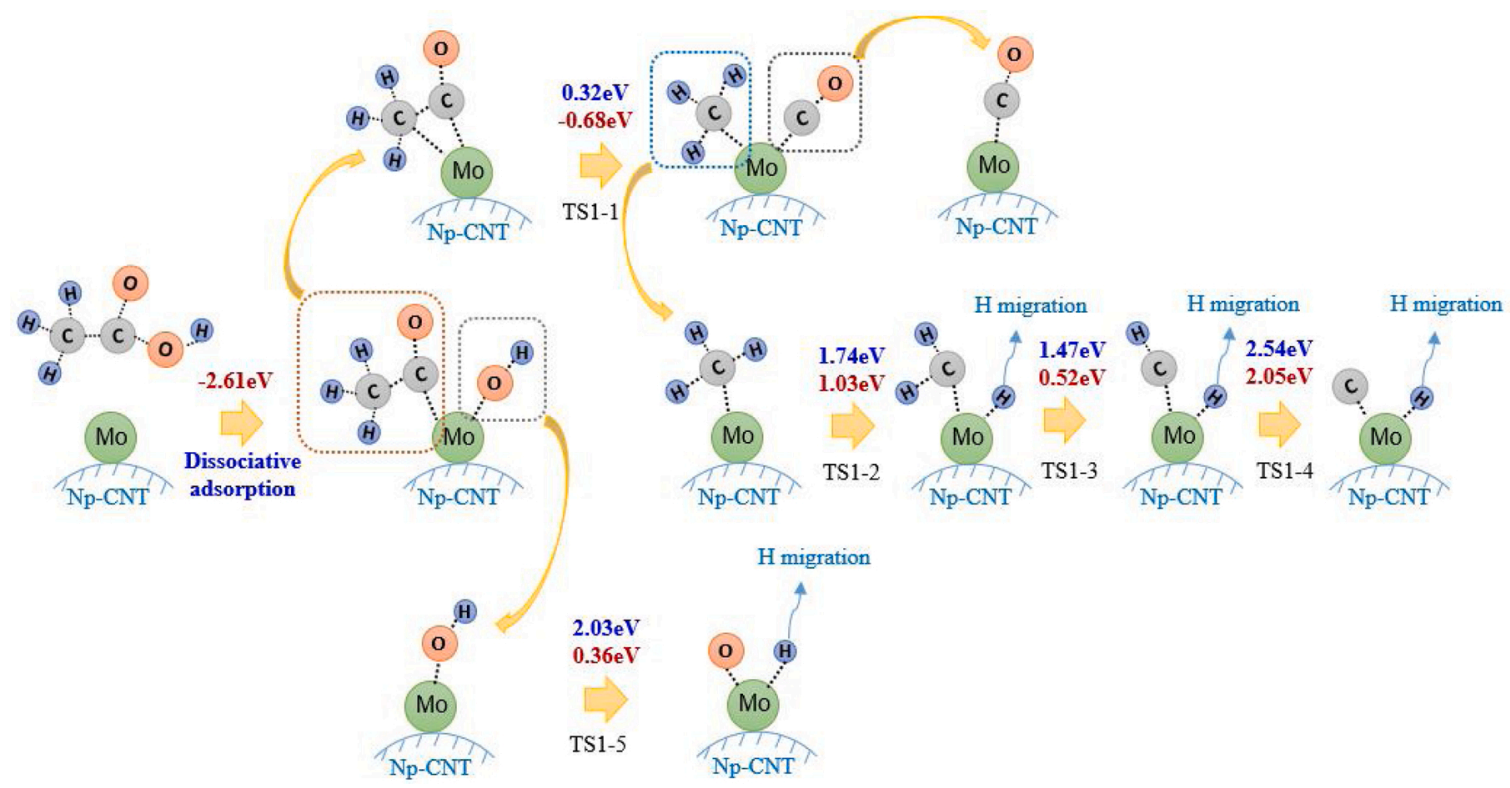

Fig. 5. Reaction flow of the decomposition of $\mathrm{AcOH}$ over $\mathrm{Mo} / \mathrm{N}_{\mathrm{p}}$-CNT (Blue font denotes energy barrier and violet denotes reaction energy).

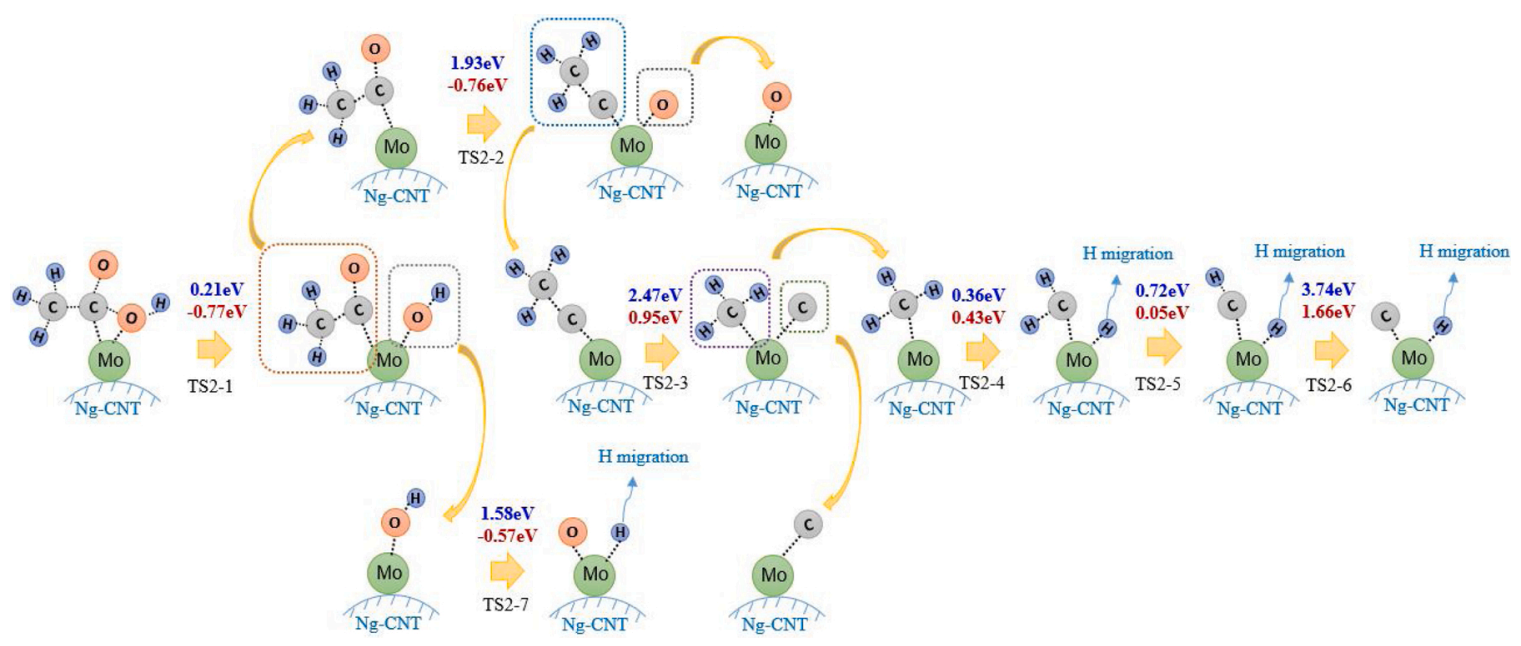

Fig. 6. Reaction flow of the decomposition of $\mathrm{AcOH}$ over $\mathrm{Mo} / \mathrm{N}_{\mathrm{g}}$-CNT (Blue font denotes energy barrier and violet denotes reaction energy).

In comparison with the free molecular decomposition of AcOH [4], shown in Fig. 4, the cleavage energy of each bond in $\mathrm{AcOH}$ has been significantly decreased, suggesting that both Mo/N-CNT catalysts facilitate the decomposition of $\mathrm{AcOH}$. The modelling results predict hydroxyl cleavage occurred at the beginning of the $\mathrm{AcOH}$ decomposition over both types of Mo/N-CNTs, which is different from the pathways over pure metal facets e.g. Mo and Rh [4,57]. Specifically, the formation of acetate is supressed at the beginning of reaction, and the donation of methyl hydrogens occurs as final steps over both types of Mo/N-CNT.

Driven by its electrophilicity (electron acceptor) property, $\mathrm{Mo} / \mathrm{N}_{\mathrm{p}^{-}}$ $\mathrm{CNT}$ gives rise to a barrier-free dissociation during the $\mathrm{AcOH}$ adsorption, whereas $\mathrm{Mo} / \mathrm{N}_{\mathrm{g}}$-CNT leads to a small energy barrier for the same decomposition. The modelling predicts different favourable pathways for $\mathrm{AcOH}$ decomposition over the two Mo/N-CNTs catalysts. $\mathrm{Mo} / \mathrm{N}_{\mathrm{p}^{-}}$ CNT favours the $\mathrm{C}-\mathrm{C}$ cleavage with an energy barrier of $0.32 \mathrm{eV}$, which is significantly lower than that in the reaction over a pure Mo slab with an energy barrier of $4.22 \mathrm{eV}$. This is in perfect agreement with a commonly reported favourable reaction pathway for $\mathrm{AcOH}$ decomposition $[10,14,58]$, with the merit of few hurdles before the hydrogen donation, while the release of the four hydrogens from the lower fragments of methyl and hydroxyl are mostly endothermic processes with higher energy barriers. This may ease $\mathrm{CH}_{4}$ and $\mathrm{CO}$ formation during the hydrogen donation process [10,59]. In contrast, the release of methyl $\mathrm{H}$ and the hydroxyl $\mathrm{H}$ show smaller energy barriers over $\mathrm{Mo} / \mathrm{N}_{\mathrm{g}}$-CNT than over Mo/ $\mathrm{N}_{\mathrm{p}}$-CNT, indicating the dedicated function of $\mathrm{Mo} / \mathrm{N}_{\mathrm{g}}-\mathrm{CNT}$ in facilitating the dissociation of the $\mathrm{C}-\mathrm{H}$ bond. However, the hydrogen donation has to first overcome the early stage decomposition steps with much higher energy barriers such as $\mathrm{C}-\mathrm{O}_{\alpha}$ and $\mathrm{C}-\mathrm{C}$ cleavages.

\subsection{Dehydrogenation of formic acid over Mo/N-CNTs}

The adsorption of FA over Mo/ $\mathrm{N}_{\mathrm{p}}$-CNT and $\mathrm{Mo} / \mathrm{N}_{\mathrm{g}}-\mathrm{CNT}$ in a variety of configurations was modelled and the adsorption energies are compared in Table 3. The corresponding configurations are shown in Table S1. The free molecular structure of FA and the associated BDEs of each bonds are shown in Fig. 7. The results reveal that the FA molecule binding to the catalyst via a $\mathrm{C}-\mathrm{Mo}$ bond led to the largest adsorption energies, for $-3.54 \mathrm{eV}$ over $\mathrm{Mo} / \mathrm{N}_{\mathrm{p}}$-CNT and $-2.75 \mathrm{eV} \mathrm{Mo} / \mathrm{N}_{\mathrm{g}}-\mathrm{CNT}$, respectively, followed by the binding through the $\mathrm{O}_{\alpha}-$ Mo bond over 
Table 3

Adsorption energy of FA onto Mo/N-CNTs with different configurations.

\begin{tabular}{lccc}
\hline Ead (FA) (eV) & C-Mo & $\mathrm{O}_{\alpha}$-Mo & $\mathrm{O}_{\beta}-\mathrm{Mo}$ \\
\hline $\mathrm{Mo} / \mathrm{N}_{\mathrm{p}}$-CNT & -3.54 & -1.74 & $-0.81^{*}$ \\
$\mathrm{Mo} / \mathrm{N}_{\mathrm{g}}$-CNT & -2.75 & -1.55 & -1.15 \\
\hline
\end{tabular}

* Only stable weak adsorption observed.

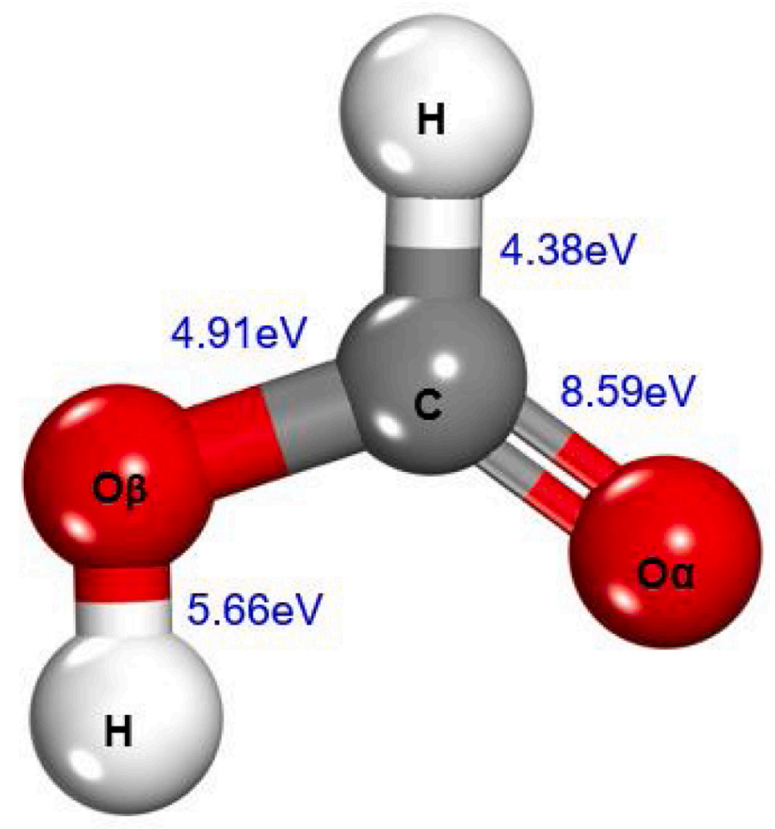

Formic acid molecule

Fig. 7. FA molecule with cleavage energy barriers (blue font) in free molecule [4].

$\mathrm{Mo} / \mathrm{N}_{\mathrm{p}}$-CNT $(-1.75 \mathrm{eV})$ and $\mathrm{Mo} / \mathrm{N}_{\mathrm{g}}$-CNT $(-1.55 \mathrm{eV})$. FA adsorption via the $\mathrm{O}_{\beta}-$ Mo bond resulted in the lowest adsorption energies compared to other configurations with energies of $-0.81 \mathrm{eV}$ over $\mathrm{Mo} / \mathrm{N}_{\mathrm{p}}$-CNT and $-1.15 \mathrm{eV}$ over $\mathrm{Mo} / \mathrm{N}_{\mathrm{g}}$-CNT. Interestingly, the dissociative adsorption was observed for FA adsorption over both catalysts, which happens to AcOH only over $\mathrm{Mo} / \mathrm{N}_{\mathrm{p}}$-CNT. The most favourable reaction pathways for FA adsorption and decomposition in both cases are depicted in Figs. 8 and 9 respectively. More details regarding the parallel reactions are shown in Table S3.

Over $\mathrm{Mo} / \mathrm{N}_{\mathrm{p}}-\mathrm{CNT}$, the dissociation amid the adsorption of FA led to the simultaneous barrier-free cleavage of $\mathrm{C}-\mathrm{H}$ and $\mathrm{C}-\mathrm{O}_{\beta}$ with the adsorption energy of $-3.54 \mathrm{eV}$, producing three lower fragments of bonded $\mathrm{CO}$, hydroxyl and $\mathrm{H}$ atom. The other hydrogen release from hydroxyl showed a $1.98 \mathrm{eV}$ intrinsic energy barrier with the reaction energy of $0.41 \mathrm{eV}$. Over $\mathrm{Mo} / \mathrm{N}_{\mathrm{g}}$-CNT, the FA molecule underwent analogous dissociative adsorption without any energy barriers and produced aldehyde and hydroxyl fragments. The aldehyde $\mathrm{H}$ was then cleaved with a small energy barrier of $0.36 \mathrm{eV}$ during an exothermic reaction with $-1.34 \mathrm{eV}$ energy, and the hydroxyl cleavage would release the other $\mathrm{H}$ atom in a $-0.49 \mathrm{eV}$ exothermic process, with an energy barrier of $1.57 \mathrm{eV}$.

The reactions involved in FA decomposition over both catalysts are facilitated through lower intrinsic energy barriers compared to the free molecule scenario (Fig. 7). The model also predicts that Mo/N-CNTs give rise to different favourable reaction pathways of FA decomposition in comparison with common catalysts $[19,60,61]$. Instead of the formation of carboxylic or formate intermediates, the dehydroxylation reaction occurs at the beginning, giving rise to facile hydrogen donation at the early stage. The dehydroxylation is also reported to take place over the $\mathrm{Cu}$ (111) facet, but normally with a higher energy barrier [6]. Compared to the decomposition of FA over pure Mo [4], Mo/N-CNTs exhibit better performance in terms of facilitating hydrogen donation by lowering the energy barriers and by decreasing the number of reaction steps.

The two $\mathrm{H}$ atoms in the FA molecule show different readiness for donation over the catalysts. Modelling results predict that the $\mathrm{H}-\mathrm{C}$ bond is more likely to cleave over Mo/N-CNTs compared to the hydroxyl $\mathrm{H}$. Especially, $\mathrm{N}_{\mathrm{p}}$ doped $\mathrm{CNT}$ induces barrier-free $\mathrm{H}$ release during the adsorption, which is comparable to $\mathrm{H}_{2}$ dissociation over the transition metal surface. The $\mathrm{C}-\mathrm{H}$ bond cleavage was unfavourable in some circumstances, e.g. over a Mo slab or a Pd/C catalyst [4,62], but it turns out to be much facile over both catalysts in this study. In comparison, the release of hydroxyl $\mathrm{H}$ is more difficult than aldehyde $\mathrm{H}$, therefore leading to the peak energy barrier of FA decomposition over both $\mathrm{Mo} / \mathrm{N}-\mathrm{CNTs}$. It is found also that $\mathrm{Mo} / \mathrm{N}_{\mathrm{g}}-\mathrm{CNT}$ leads to a smaller energy barrier for the release of hydroxyl $\mathrm{H}$ than $\mathrm{Mo} / \mathrm{N}_{\mathrm{p}}$-CTN does. But it is also noteworthy that the dissociative adsorption energy of $\mathrm{FA}$ over $\mathrm{Mo} / \mathrm{N}_{\mathrm{p}}$-CNT is much larger than that for $\mathrm{Mo} / \mathrm{N}_{\mathrm{g}}-\mathrm{CNT}$, which could potentially contribute to the consequent cleavage of hydroxyl and the hydrogen donation (migration) by preventing the formation of $\mathrm{H}_{2} \mathrm{O}$ [19].

The modelling has predicted different potentials of hydrogen donation for FA and $\mathrm{AcOH}$. Despite the larger number of $\mathrm{H}$ atoms in $\mathrm{AcOH}$, FA has a greater potential for in-situ hydrogen donation over both Mo/ $\mathrm{N}$-CNTs catalysts, especially in mild temperature conditions. This is mainly attributed to the facile cleavage of the $\mathrm{C}-\mathrm{H}$ bond during the initial step of interaction between FA and Mo/N-CNT catalysts, as shown in Figs. 8 and 9.

\subsection{Electron density difference (EDD) and atomic charge analyses for typical groups}

The reaction modelling results indicate that $\mathrm{Mo} / \mathrm{N}_{\mathrm{g}}-\mathrm{CNT}$ and $\mathrm{Mo} / \mathrm{N}_{\mathrm{p}^{-}}$ CNT show different performances in facilitating hydrogen donation by affecting the decomposition of typical groups. Specifically, Mo/ $\mathrm{N}_{\mathrm{g}}$-CNT is capable of preferentially activating $\mathrm{O}-\mathrm{H}$ and $\mathrm{C}-\mathrm{Hbonds}$, and $\mathrm{Mo} /$ Np-CNT would enable the ready cleavage of the $\mathrm{C}-\mathrm{C}$ bond. To gain new insights into the interaction between the catalysts and reactants, an electron density difference (EDD) analysis was carried out on the typical intermediate groups of acetyl, methyl and hydroxyl over both catalysts, as shown in Figs. 10-12. Atomic charge was also calculated and assigned to each atom as an indicator for interatomic covalency (Table S4).

The analysis reveals that $\mathrm{N}_{\mathrm{p}}$ and $\mathrm{N}_{\mathrm{g}}$ give rise to different electronegativity effects towards the lower fragment groups, and this is consistent with the catalytic property of both doping types. For the acetyl over Mo/ $\mathrm{N}_{\mathrm{p}}$-CNT, electron loss and enrichment were both found around $\mathrm{C}_{\beta}$, and mainly electron enrichment around methyl and oxygen is observed. As a result, $\mathrm{C}_{\beta}$ and methyl tend to be electronically neutral prior to the cleavage, evidenced by the net group charges of 0.01 and 0.00 , respectively (Table S4). In the case of Mo/ $\mathrm{N}_{\mathrm{g}}$-CNT, Mo had less electron loss, but there was more electron enrichment to make the $\mathrm{C}_{\beta}$ absolute electric neutral (charge $=0.00$ ), owing to less electron enrichment on $\mathrm{N}_{\mathrm{g}}$ and the delocalised electron compensation from $\mathrm{N}_{\mathrm{g}}$. However, fewer electrons were found to migrate to the methyl group in this circumstance, leading to an overall positive charge (0.08) for the methyl in acetyl over $\mathrm{Mo} / \mathrm{N}_{\mathrm{g}}$-CNT. The electronic analyses elucidate the modelling results that the cleavage of the $\mathrm{C}-\mathrm{C}$ bond is much more facilitated by $\mathrm{Mo} / \mathrm{N}_{\mathrm{p}}$-CNT; the catalyst enables more electrons loss on $\mathrm{Mo}$, so that it reinforces the Mo- $\mathrm{C}_{\beta}$ bond. Simultaneously, it gives rise to electron enrichment on $\mathrm{C}_{\beta}$ and the methyl group, which eventually reduces the strength of the $\mathrm{C}-\mathrm{C}$ bond and makes it ready to cleave. This is confirmed by the difference in the $\mathrm{C}-\mathrm{C}$ bond length $(1.526 \AA$ and 1.490 $\AA$ ) over the two catalysts, as shown in Fig. 10. Such a mechanism is also supposed to contribute to the stabilisation of the $\mathrm{Mo}-\mathrm{O}_{\beta}$ bond and the consequent dissociative adsorption of $\mathrm{AcOH}$ over $\mathrm{Mo} / \mathrm{N}_{\mathrm{p}}$-CNT, where C- 


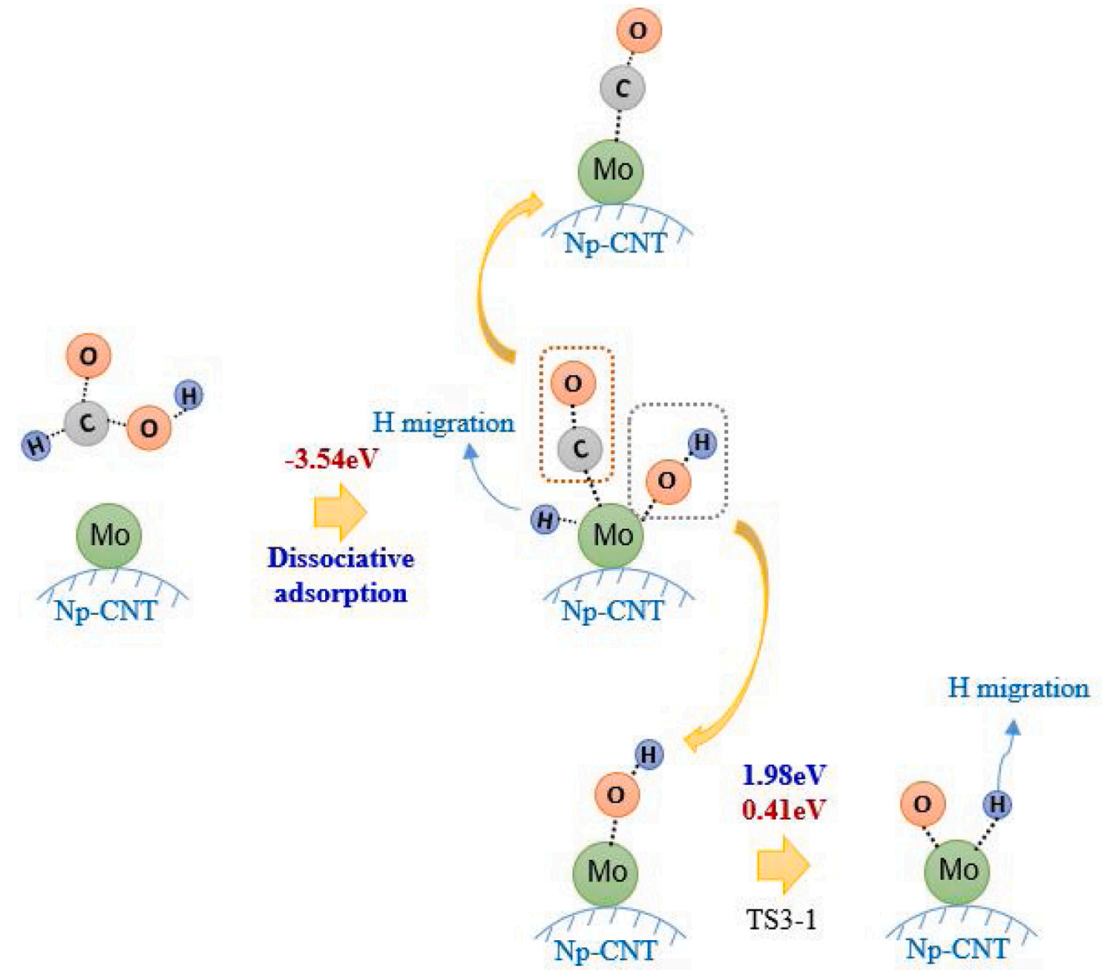

Fig. 8. Reaction flow of the decomposition of FA over Mo/ $\mathrm{N}_{\mathrm{p}}-\mathrm{CNT}$ (Blue font denotes energy barrier, and violet denotes reaction energy).

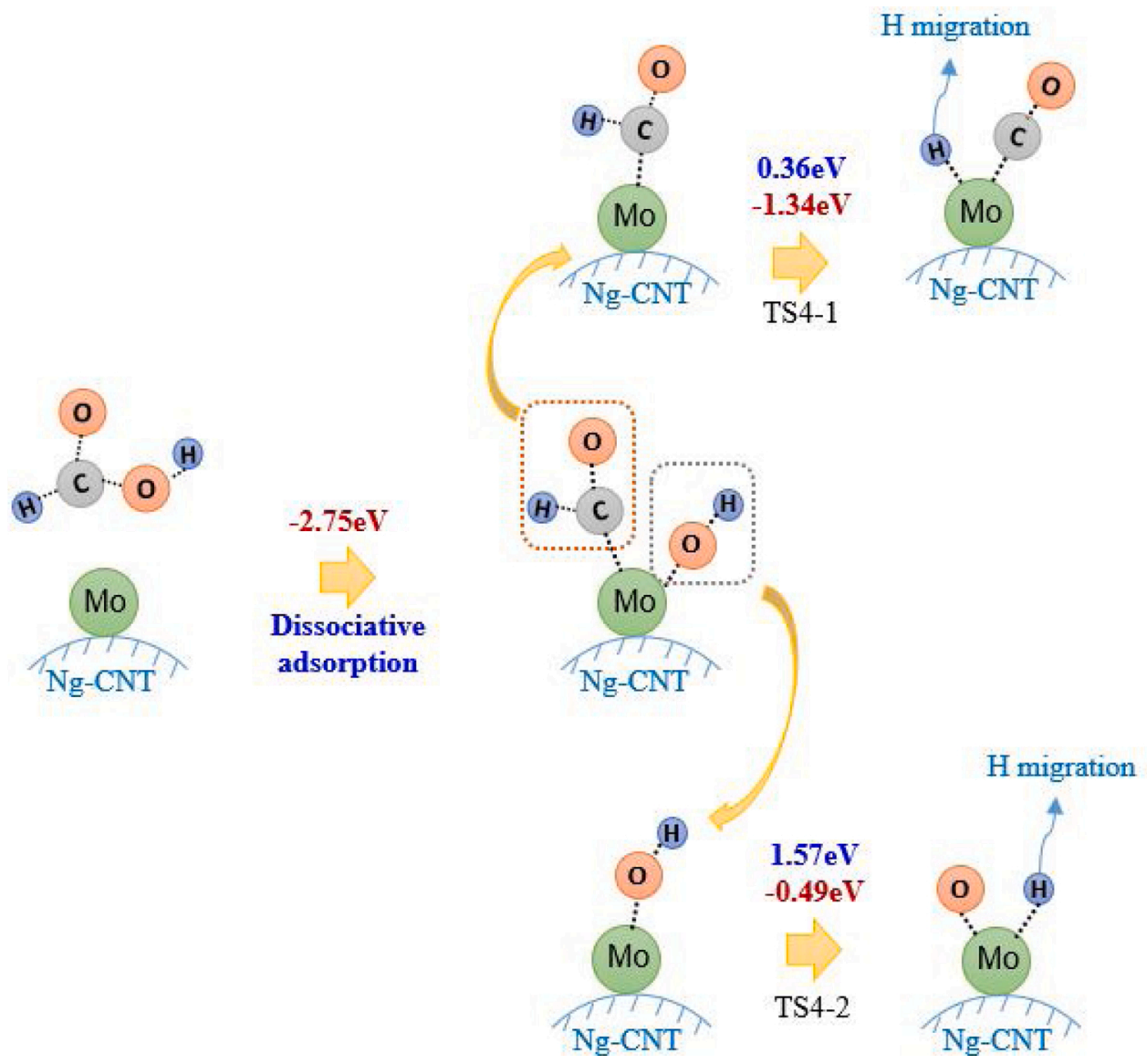

Fig. 9. Flow chart for the decomposition reaction of FA over Mo/ $\mathrm{N}_{\mathrm{g}}$-CNT (Blue font denotes energy barrier and violet denotes reaction energy). 


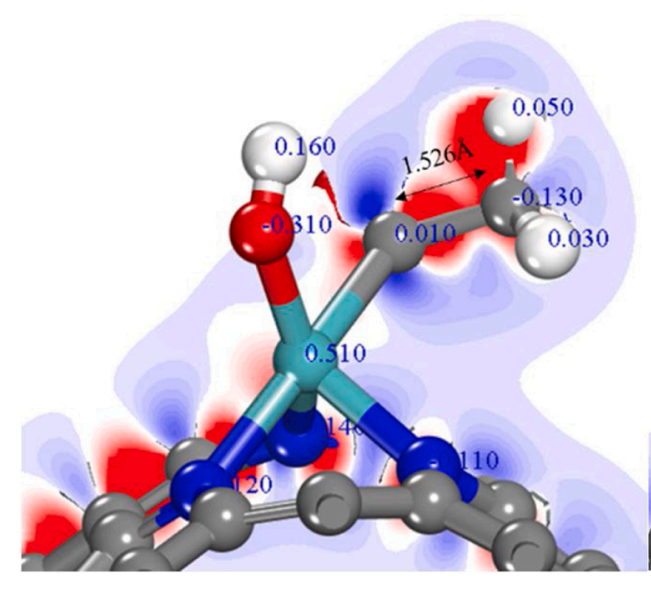

(a)

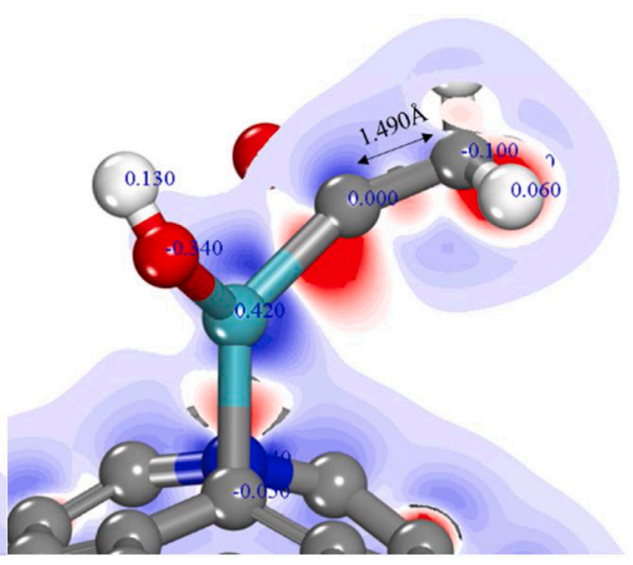

(b)

Fig. 10. EDD analyses (threshold value: $+/-0.2$ electrons $/ \AA^{3}$ ) of the $\mathrm{C}-\mathrm{C}$ bond structures with atomic charges on (a) Mo/ $\mathrm{N}_{\mathrm{p}}-\mathrm{CNT}$ (b) Mo/N $\mathrm{N}_{\mathrm{g}}-\mathrm{CNT}$. Red denotes electron enrichment and blue denotes electron loss.

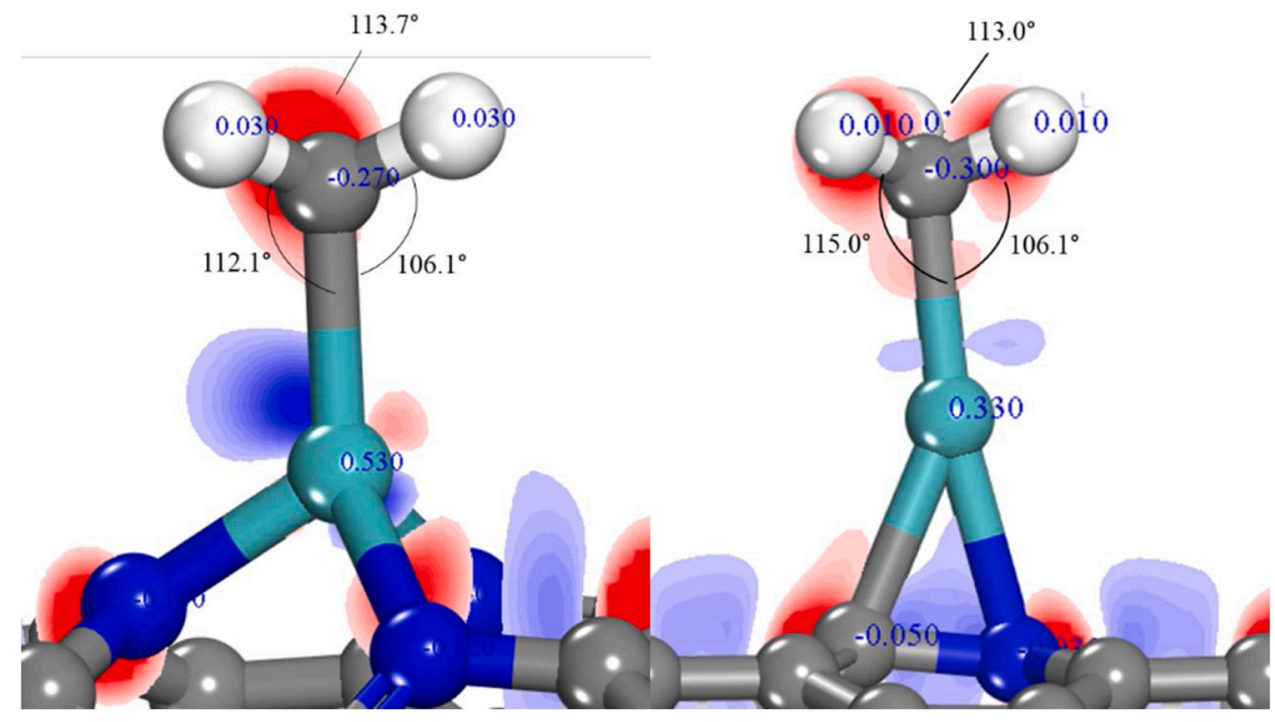

(a)

(b)

Fig. 11. EDD analyses (threshold value: $+/-0.2$ electrons $/ \AA^{3}$ ) of the methyl groups with atomic charges on (a) Mo/ $\mathrm{N}_{\mathrm{p}}-\mathrm{CNT}$ (b) Mo/ $\mathrm{N}_{\mathrm{g}}$-CNT. Red denotes electron enrichment and blue denotes electron loss.

$\mathrm{O}_{\beta}$ cleaves. Besides, the results also imply that methyl cleavage from acetyl in these circumstances tends to be homolytic, evidenced by the atomic charge analyses of the corresponding transition states (Fig. S6).

Regarding the adsorbed methyl, electron enrichment around carbon was observed when it was adsorbed on $\mathrm{Mo} / \mathrm{N}_{\mathrm{p}}-\mathrm{CNT}$, mainly resulting from the electron loss of Mo. In contrast, the methyl group in bulk gained more electrons over Mo/ $\mathrm{N}_{\mathrm{g}}$-CNT (Table S4), revealing the effect of the delocalised electron from graphitic doping of $\mathrm{N}$. It is noteworthy that not only the $\mathrm{C}$ atom, but also the $\mathrm{H}$ atoms are electron enriched in such circumstance, resulting in near charge neutrality of the $\mathrm{H}$ atoms and consequently facilizing the hydron donation, analogues to those in the $\mathrm{H}_{2}$ molecule. More obvious activation of the $\mathrm{C}-\mathrm{H}$ bond over $\mathrm{Mo} / \mathrm{N}_{\mathrm{g}}$ CNT can be observed in Fig. 11 based on the increased $\mathrm{Mo}-\mathrm{C}-\mathrm{H}$ bond angle (to $115.0^{\circ}$ ), compared to that over $\mathrm{Mo} / \mathrm{N}_{\mathrm{p}}$ - CNT and $109.5^{\circ}$ in common $\mathrm{CH}_{3}{ }^{*}$ tetrahedron structure. The results are in line with the reaction modelling results, and also suggest that methyl is more likely to release hydrogen through homolytic cleavage over Mo/N-CNTs (this is also evidenced by the atomic charge analyses of the corresponding transition states in Fig. S6), benefiting from the electron enrichment between $\mathrm{C}-\mathrm{H}$.

For the adsorbed hydroxyl, less electron loss (more electron back donation) to the $\mathrm{H}$ atom was found to take place over $\mathrm{Mo} / \mathrm{N}_{\mathrm{g}}-\mathrm{CNT}$, as shown in Fig. 12. The adsorbed structures also exhibit stronger bent (to be $129.1^{\circ}$ ) of $\angle \mathrm{MoOH}$ over Mo/ $\mathrm{N}_{\mathrm{g}}$-CNT, compared to that $\left(137.7^{\circ}\right)$ over $\mathrm{Mo} / \mathrm{N}_{\mathrm{p}}-\mathrm{CNT}$, indicating $\mathrm{O}-\mathrm{H}$ is more activated in this case, with strengthened covalent character of the $\mathrm{Mo}-\mathrm{OH}$ bond [63]. The release of hydroxyl $\mathrm{H}$ is thus facilitated compared to that over $\mathrm{Mo} / \mathrm{N}_{\mathrm{p}}-\mathrm{CNT}$. Nevertheless, even though Mo has similar electron loss to that binding to the methyl group, the hydroxyl $\mathrm{H}$ is not charge neutrality, but carries positive charges over both catalysts (Table S4). This may be because of the large electronegativity of oxygen, giving rise to higher energy barriers for the homolytic cleavage (Fig. S6) of $\mathrm{H}-\mathrm{O} *$ than ${ }^{*} \mathrm{CH}_{2}-\mathrm{H}$. The 


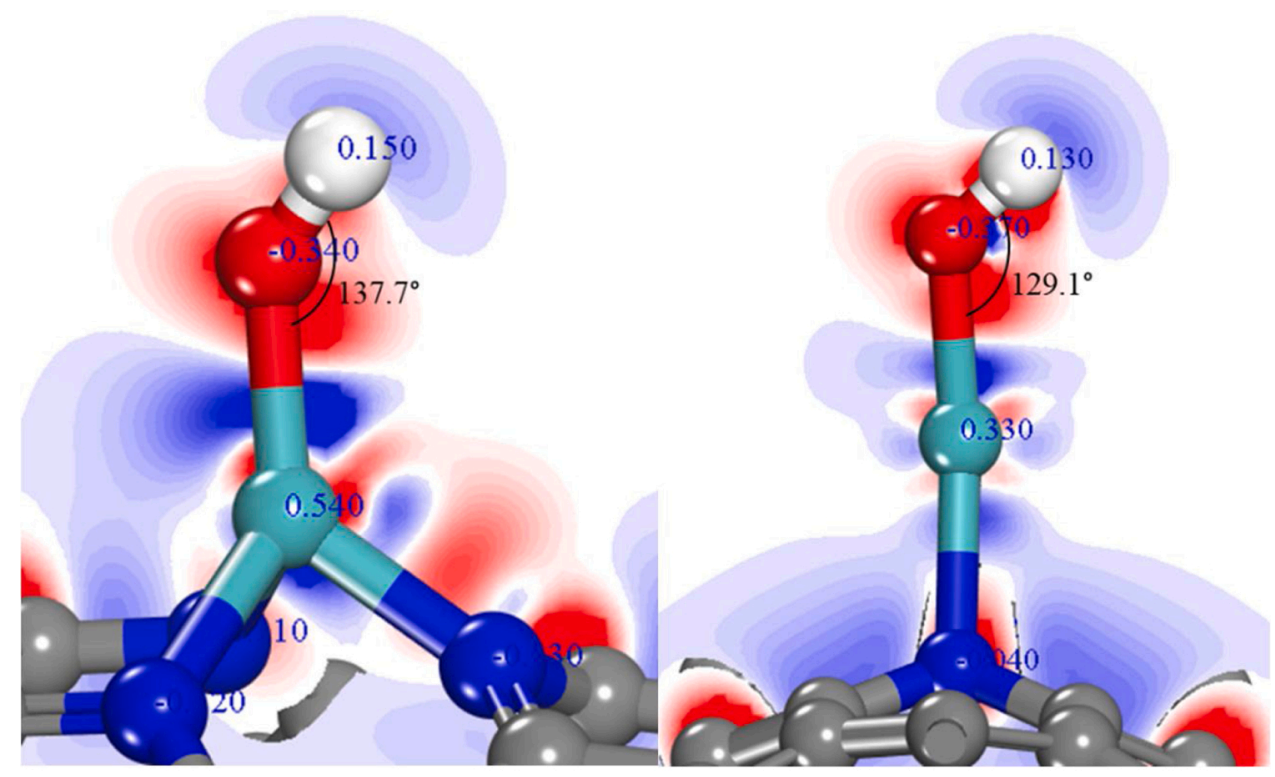

(a)

(b)

Fig. 12. EDD analyses (threshold value: $+/-0.2$ electrons $/ \AA^{3}$ ) of the hydroxyl groups with atomic charges on (a) Mo/ $\mathrm{N}_{\mathrm{p}}$-CNT (b) Mo/ $\mathrm{N}_{\mathrm{g}}$-CNT. Red denotes electron enrichment and blue denotes electron loss.

homolytic cleavages of hydroxyl during acid decomposition would require more electron enrichment. This agrees with the reaction modelling results shown in Figs. 5 and 6.

Generally, the results of EDD analyses in this study suggest that Mo/ $\mathrm{N}_{\mathrm{p}}$-CNT would facilitate the C-C cleavage, and $\mathrm{Mo} / \mathrm{N}_{\mathrm{g}}$-CNT favours the cleavage of $\mathrm{H}$ contained bonds, eventually benefiting the in-situ $\mathrm{H}$ donation.

\section{Conclusions}

This study provided predictions of the hydrogen donation behaviour of bio-acids over the metal loaded N-doped CNTs by DFT calculation. Ten different transition metals and six CNT-based catalysts were modelled. Adsorption modelling indicated that the Mo/ $\mathrm{N}_{\mathrm{p}}$-CNT catalyst gave rise to the strongest binding with the adsorbed acid molecule, followed by Mo/CNT and Mo/ $\mathrm{N}_{\mathrm{g}}-\mathrm{CNT}$. The reaction modelling of the decomposition of $\mathrm{AcOH}$ and FA was carried out based on the catalysts of $\mathrm{Mo} / \mathrm{N}_{\mathrm{p}}$-CNT and $\mathrm{Mo} / \mathrm{N}_{\mathrm{g}}-\mathrm{CNT}$, with the emphasis on the $\mathrm{H}$ related bond cleavages. The results revealed that Mo/N-CNTs significantly lowered the decomposition energy barriers for both $\mathrm{AcOH}$ and FA, while different types of $\mathrm{N}$ doping gave rise to various reaction pathways. The most favourable reaction pathways for the decomposition of AcOH over $\mathrm{Mo} / \mathrm{N}_{\mathrm{p}}$-CNT and $\mathrm{Mo} / \mathrm{N}_{\mathrm{g}}$-CNT were $\mathrm{CH}_{3} \mathrm{COOH} \rightarrow \mathrm{CH}_{3} \mathrm{CO} \rightarrow \mathrm{CH}_{3} \rightarrow \mathrm{CH}_{2}$ $\rightarrow \mathrm{CH} \rightarrow \mathrm{C}$, and $\mathrm{CH}_{3} \mathrm{COOH} \rightarrow \mathrm{CH}_{3} \mathrm{CO} \rightarrow \mathrm{CH}_{3} \mathrm{C} \rightarrow \mathrm{CH}_{3} \rightarrow \mathrm{CH}_{2} \rightarrow \mathrm{CH}_{1} \rightarrow \mathrm{C}$, respectively. In comparison, FA experienced barrier-free decomposition and released hydrogen through $\mathrm{HCOOH} \rightarrow \mathrm{H}+\mathrm{CO}+\mathrm{OH}$, during its adsorption over Mo/ $\mathrm{N}_{\mathrm{p}}-\mathrm{CNT}$. Over $\mathrm{Mo} / \mathrm{N}_{\mathrm{g}}-\mathrm{CNT}$, FA underwent similar dissociative adsorption through $\mathrm{HCOOH} \rightarrow \mathrm{HCO}+\mathrm{OH}$, where aldehyde $\mathrm{H}$ could be released with a small energy barrier of $0.36 \mathrm{eV}$. The hydroxyl $\mathrm{H}$ release exhibited larger energy barriers over both catalysts. Further electronic analyses revealed that $\mathrm{Mo} / \mathrm{N}_{\mathrm{p}}$-CNT would selectively facilitate the homolytic cleavage of the $\mathrm{C}-\mathrm{C}$ bond, whereas $\mathrm{Mo} / \mathrm{N}_{\mathrm{g}}-\mathrm{CNT}$ would promote the homolytic cleavage of $\mathrm{C}-\mathrm{H}$ and $\mathrm{O}-\mathrm{H}$, through electron enrichment. The modelling work also predicted that FA has a superior hydrogen donating capability to AcOH over the Mo/N-CNT catalysts due to lower energy barriers, suggesting the in-situ hydrogen donation of FA would potentially occur in milder conditions than that of $\mathrm{AcOH}$.

\section{Notes}

All authors agree with the content and submission of this original research, and we confirm that the manuscript is not being considered for publication elsewhere. Jiajun Zhang carried out the research and prepared the original draft of the manuscript; Xiaolei Zhang (corresponding author) did proof reading and finalised the manuscript; Amin Osatiashtiani did review and revision to the manuscript, Kai Hong Luo, Dekui Shen, Jun Li and Anthony Bridgwater contributed to technical discussions and proof reading of the manuscript. The authors declare no competing financial interest.

\section{Credit author statement}

All authors agree with the content and submission of this original research, and we confirm that the manuscript is not being considered for publication elsewhere. Jiajun Zhang carried out the research and prepared the original draft of the manuscript; Xiaolei Zhang (corresponding author) did proof reading and finalised the manuscript; Amin Osatiashtiani did review and revision to the manuscript, Kai Hong Luo, Dekui Shen, Jun Li and Anthony Bridgwater contributed to technical discussions and proof reading of the manuscript. The authors declare no competing financial interest.

\section{Declaration of Competing Interest}

The authors report no declarations of interest.

\section{Acknowledgement}

The authors would like to acknowledge financial support from the Leverhulme Trust Research Grant (RPG-2017-254) and EPSRC First Grant (EP/R010986/1). The authors are also grateful for computational support from the UK Materials and Molecular Modelling Hub, which is partially funded by the EPSRC (EP/P020194/1), for which access was obtained via the UKCP consortium and funded by EPSRC Grant (EP/ P022561/1). Additional computational resources from the EPSRC under the project UK Consortium on Mesoscale Engineering Sciences 
(UKCOMES) (Grant No. EP/R029598/1) are also gratefully acknowledged.

\section{Appendix A. Supplementary data}

Supplementary material related to this article can be found, in the online version, at doi:https://doi.org/10.1016/j.mcat.2020.111289.

\section{References}

[1] P. Friedlingstein, M.W. Jones, M.O. Sullivan, R.M. Andrew, J. Hauck, G.P. Peters, W. Peters, J. Pongratz, S. Sitch, C. Le Quéré, Global Carbon Budget 2019, 2019, pp. 1783-1838.

[2] T. Bridgwater, Challenges and opportunities in fast pyrolysis of biomass: part I, Johnson Matthey Technol. Rev. 62 (2018) 118-130, https://doi.org/10.1595/ 205651318 X696693.

[3] A. Osatiashtiani, A.F. Lee, K. Wilson, Recent advances in the production of $\gamma$-valerolactone from biomass-derived feedstocks via heterogeneous catalytic transfer hydrogenation, J. Chem. Technol. Biotechnol. 92 (2017) 1125-1135, https://doi.org/10.1002/jctb.5213.

[4] J. Zhang, X. Zhang, A. Osatiashtiani, A. Bridgwater, Hydrogen donation of bioacids over transition metal facets: a density functional theory study, Appl. Catal. A Gen. 586 (2019) 117218, https://doi.org/10.1016/j.apcata.2019.117218.

[5] K. Müller, K. Brooks, T. Autrey, Hydrogen storage in formic acid: a comparison of process options, Energy Fuels 31 (2017) 12603-12611, https://doi.org/10.1021/ acs.energyfuels.7b02997.

[6] Z. Jiang, P. Qin, T. Fang, Decomposition mechanism of formic acid on Cu (111) surface: a theoretical study, Appl. Surf. Sci. 396 (2017) 857-864, https://doi.org/ 10.1016/j.apsusc.2016.11.042.

[7] C. Hu, S.-W. Ting, K.-Y. Chan, W. Huang, Reaction pathways derived from DFT for understanding catalytic decomposition of formic acid into hydrogen on noble metals, Int. J. Hydrogen Energy 37 (2012) 15956-15965, https://doi.org/ 10.1016/j.ijhydene.2012.08.035.

[8] Y. Huang, X. Dong, Y. Yu, M. Zhang, Comparative kinetic monte Carlo study of acetic acid decomposition to surface carbon species and undesirable byproducts on $\mathrm{Pd}(100)$ and $\mathrm{Pd} / \mathrm{Au}(100)$ from density functional theory-based calculations, J. Phys. Chem. C 121 (2017) 26733-26741, https://doi.org/10.1021/acs. jpcc.7b05072.

[9] M.J. Gilkey, B. Xu, Heterogeneous catalytic transfer hydrogenation as an effective pathway in biomass upgrading, ACS Catal. 6 (2016) 1420-1436, https://doi.org/ 10.1021/acscatal.5b02171.

[10] A.M. Verma, N. Kishore, Decomposition of acetic acid over $\mathrm{Ru}$ and $\mathrm{Ru} / \mathrm{MgO}$ catalyst clusters under DFT framework, Chem. Phys. Lett. 711 (2018) 156-165, https://doi.org/10.1016/j.cplett.2018.09.030.

[11] X. Li, S. Wang, Y. Zhu, G. Yang, P. Zheng, DFT study of bio-oil decomposition mechanism on a Co stepped surface: acetic acid as a model compound, Int. J. Hydrogen Energy 40 (2015) 330-339, https://doi.org/10.1016/j. ijhydene.2014.11.004.

[12] K.I. Gursahani, R. Alcalá, R.D. Cortright, J.A. Dumesic, Reaction kinetics measurements and analysis of reaction pathways for conversions of acetic acid, ethanol, and ethyl acetate over silica-supported Pt, Appl. Catal. A Gen. 222 (2001) 369-392, https://doi.org/10.1016/S0926-860X(01)00844-4.

[13] R. Alcala, J.W. Shabaker, G.W. Huber, M.A. Sanchez-Castillo, J.A. Dumesic, Experimental and DFT studies of the conversion of ethanol and acetic acid on PtSnBased catalysts, J. Phys. Chem. B 109 (2005) 2074-2085, https://doi.org/ 10.1021/jp049354t.

[14] M.H. Brijaldo, H.A. Rojas, J.J. Martínez, F.B. Passos, Effect of support on acetic acid decomposition over palladium catalysts, J. Catal. 331 (2015) 63-75, https:// doi.org/10.1016/j.jcat.2015.08.019.

[15] A. Neitzel, Y. Lykhach, V. Joha, N. Tsud, K.C. Prince, J. Libuda, Decomposition of acetic acid on model Pt / CeO 2 catalysts : the effect of surface crowding, J. Phys. Chem. C 119 (2015) 13721-13734, https://doi.org/10.1021/acs.jpcc.5b03079.

[16] S.M. Lang, T.M. Bernhardt, Decomposition of acetic acid mediated by free $\mathrm{Mn} \times \mathrm{O} \times$ $+(x=3,4)$ clusters, Int. J. Mass Spectrom. 433 (2018) 7-10, https://doi.org/ 10.1016/j.ijms.2018.07.008.

[17] H. Yan, X. Feng, Y. Liu, C. Yang, H. Shan, Catalytic cracking of acetic acid and its ketene intermediate over HZSM-5 catalyst : a density functional theory study, Mol. Catal. 437 (2017) 11-17, https://doi.org/10.1016/j.mcat.2017.04.038.

[18] M.D. Esrafili, P. Nematollahi, R. Nurazar, A density functional theory study on adsorption and decomposition of acetic acid over silicon carbide nanotubes, Synth. Met. 215 (2016) 164-169, https://doi.org/10.1016/j.synthmet.2016.02.019.

[19] F. Sanchez, M.H. Alotaibi, D. Motta, C.E. Chan-Thaw, A. Rakotomahevitra, T. Tabanelli, A. Roldan, C. Hammond, Q. He, T. Davies, A. Villa, N. Dimitratos, Hydrogen production from formic acid decomposition in the liquid phase using $\mathrm{Pd}$ nanoparticles supported on CNFs with different surface properties, Sustain. Energy Fuels. 2 (2018) 2705-2716, https://doi.org/10.1039/C8SE00338F.

[20] W. Xia, Interactions between metal species and nitrogen-functionalized carbon nanotubes, Catal. Sci. Technol. 6 (2016) 630-644, https://doi.org/10.1039/ C5CY01694K.

[21] K.M. Liew, C.H. Wong, X.Q. He, M.J. Tan, Thermal stability of single and multiwalled carbon nanotubes, Phys. Rev. B 71 (2005), 075424, https://doi.org/ 10.1103/PhysRevB.71.075424.
[22] D.S. Su, S. Perathoner, G. Centi, Nanocarbons for the development of advanced catalysts, Chem. Rev. 113 (2013) 5782-5816, https://doi.org/10.1021/ cr300367d.

[23] M.F.L. De Volder, S.H. Tawfick, R.H. Baughman, A.J. Hart, Carbon nanotubes: present and future commercial applications, Science (80-.) 339 (2013) 535-539, https://doi.org/10.1126/science.1222453.

[24] J.M. Planeix, N. Coustel, B. Coq, V. Brotons, P.S. Kumbhar, R. Dutartre, P. Geneste, P. Bernier, P.M. Ajayan, Application of carbon nanotubes as supports in heterogeneous catalysis, J. Am. Chem. Soc. 116 (1994) 7935-7936, https://doi. org/10.1021/ja00096a076.

[25] F.R. García-García, J. Álvarez-Rodríguez, I. Rodríguez-Ramos, A. Guerrero-Ruiz, The use of carbon nanotubes with and without nitrogen doping as support for ruthenium catalysts in the ammonia decomposition reaction, Carbon N. Y. 48 (2010) 267-276, https://doi.org/10.1016/j.carbon.2009.09.015.

[26] H. Miao, S. Li, Z. Wang, S. Sun, M. Kuang, Z. Liu, J. Yuan, Enhancing the pyridinic $\mathrm{N}$ content of Nitrogen-doped graphene and improving its catalytic activity for oxygen reduction reaction, Int. J. Hydrogen Energy 42 (2017) 28298-28308, https://doi.org/10.1016/j.ijhydene.2017.09.138.

[27] H. Wang, T. Maiyalagan, X. Wang, Review on recent progress in nitrogen-doped graphene: synthesis, characterization, and its potential applications, ACS Catal. 2 (2012) 781-794, https://doi.org/10.1021/cs200652y.

[28] X. Liu, W. Jia, G. Xu, Y. Zhang, Y. Fu, Selective hydrodeoxygenation of ligninderived phenols to cyclohexanols over Co-based catalysts, ACS Sustain. Chem. Eng. 5 (2017) 8594-8601, https://doi.org/10.1021/acssuschemeng.7b01047.

[29] S. Van Dommele, Nitrogen Doped Carbon Nanotubes: Synthesis, Characterization and Catalysis, Utrecht University, 2008.

[30] B. Rahzani, M. Saidi, H.R. Rahimpour, B.C. Gates, M.R. Rahimpour, Experimental investigation of upgrading of lignin-derived bio-oil component anisole catalyzed by carbon nanotube-supported molybdenum, RSC Adv. 7 (2017) 10545-10556, https://doi.org/10.1039/C6RA26121C.

[31] C. Zhou, W. Deng, X. Wan, Q. Zhang, Y. Yang, Y. Wang, Functionalized carbon nanotubes for biomass conversion: the base-free aerobic oxidation of 5-Hydroxymethylfurfural to 2,5-Furandicarboxylic acid over platinum supported on a carbon nanotube catalyst, ChemCatChem. 7 (2015) 2853-2863, https://doi.org/10.1002/ cctc. 201500352.

[32] X. Li, G. Chen, C. Liu, W. Ma, B. Yan, J. Zhang, Hydrodeoxygenation of ligninderived bio-oil using molecular sieves supported metal catalysts: a critical review, Renewable Sustainable Energy Rev. 71 (2017) 296-308, https://doi.org/10.1016/ j.rser.2016.12.057.

[33] T.-Y. Ding, Z.-G. Zhao, M.-F. Ran, Y.-Y. Yang, Superior activity of Pd nanoparticles confined in carbon nanotubes for hydrogen production from formic acid decomposition at ambient temperature, J. Colloid Interface Sci. 538 (2019) 474-480, https://doi.org/10.1016/j.jcis.2018.12.017.

[34] M.R. Nabid, Y. Bide, B. Etemadi, Ag@Pd nanoparticles immobilized on a nitrogendoped graphene carbon nanotube aerogel as a superb catalyst for the dehydrogenation of formic acid, New J. Chem. 41 (2017) 10773-10779, https:// doi.org/10.1039/C7NJ01108C.

[35] Q.Y. Bi, J.D. Lin, Y.M. Liu, H.Y. He, F.Q. Huang, Y. Cao, Dehydrogenation of formic acid at room temperature: boosting palladium nanoparticle efficiency by coupling with pyridinic-nitrogen-doped carbon, Angew. Chemie - Int. Ed. 55 (2016) 11849-11853, https://doi.org/10.1002/anie.201605961.

[36] Y. Liu, L. Huang, D. Wei, Y. Wang, H. Zhang, G. Yu, Synthesis of N-Doped graphene by chemical vapor deposition and its electrical properties, Nano Lett. 9 (2009) 1752-1758, https://doi.org/10.1021/nl803279t.

[37] S. Wang, C. Han, J. Wang, J. Deng, M. Zhu, J. Yao, H. Li, Y. Wang, Controlled synthesis of ordered mesoporous carbohydrate-derived carbons with flower-like structure and N-doping by self-transformation, Chem. Mater. 26 (2014) 6872-6877, https://doi.org/10.1021/cm503669v.

[38] Y. Cao, S. Mao, M. Li, Y. Chen, Y. Wang, Metal/porous carbon composites for heterogeneous catalysis: old catalysts with improved performance promoted by Ndoping, ACS Catal. 7 (2017) 8090-8112, https://doi.org/10.1021/ acscatal.7b02335.

[39] M. Zhao, Y. Xia, J.P. Lewis, R. Zhang, First-principles calculations for nitrogencontaining single-walled carbon nanotubes, J. Appl. Phys. 94 (2003) 2398-2402, https://doi.org/10.1063/1.1593798.

[40] X. Ning, H. Yu, F. Peng, H. Wang, Pt nanoparticles interacting with graphitic nitrogen of N-doped carbon nanotubes: effect of electronic properties on activity for aerobic oxidation of glycerol and electro-oxidation of CO, J. Catal. 325 (2015) 136-144, https://doi.org/10.1016/j.jcat.2015.02.010.

[41] T. Schiros, D. Nordlund, L. Pálová, D. Prezzi, L. Zhao, K.S. Kim, U. Wurstbauer, C. Gutiérrez, D. Delongchamp, C. Jaye, D. Fischer, H. Ogasawara, L.G. M. Pettersson, D.R. Reichman, P. Kim, M.S. Hybertsen, A.N. Pasupathy, Connecting dopant bond type with electronic structure in N-doped graphene, Nano Lett. 12 (2012) 4025-4031, https://doi.org/10.1021/nl301409h.

[42] M. Terrones, A. Jorio, M. Endo, A.M. Rao, Y.A. Kim, T. Hayashi, H. Terrones, J.C. Charlier, G. Dresselhaus, M.S. Dresselhaus, New direction in nanotube science, Mater. Today. 7 (2004) 30-45, https://doi.org/10.1016/S1369-7021(04)00447-X.

[43] W.J. Lee, U.N. Maiti, J.M. Lee, J. Lim, T.H. Han, S.O. Kim, Nitrogen-doped carbon nanotubes and graphene composite structures for energy and catalytic applications, Chem. Commun. 50 (2014) 6818, https://doi.org/10.1039/ c4cc00146j.

[44] Q. Wei, X. Tong, G. Zhang, J. Qiao, Q. Gong, S. Sun, Nitrogen-doped carbon nanotube and graphene materials for oxygen reduction reactions, Catalysts 5 (2015) 1574-1602, https://doi.org/10.3390/catal5031574.

[45] X. Ning, Y. Li, J. Ming, Q. Wang, H. Wang, Y. Cao, F. Peng, Y. Yang, H. Yu, Electronic synergism of pyridinic- and graphitic-nitrogen on $\mathrm{N}$-doped carbons for 
the oxygen reduction reaction, Chem. Sci. 10 (2019) 1589-1596, https://doi.org/ 10.1039/C8SC04596H.

[46] B. Delley, An all-electron numerical method for solving the local density functiona for polyatomic molecules, J. Chem. Phys. 92 (1990) 508-517, https://doi.org/ $10.1063 / 1.458452$.

[47] M.D. Segall, P.J.D. Lindan, M.J. Probert, C.J. Pickard, P.J. Hasnip, S.J. Clark, M C. Payne, First-principles simulation: ideas, illustrations and the CASTEP code, J. Phys. Condens. Matter 14 (2002) 2717-2744, https://doi.org/10.1088/0953 8984/14/11/301.

[48] J.P. Perdew, K. Burke, M. Ernzerhof, Generalized gradient approximation made simple, Phys. Rev. Lett. 77 (1996) 3865-3868, https://doi.org/10.1103/ PhysRevLett.77.3865.

[49] S. Grimme, Semiempirical GGA-type density functional constructed with a longrange dispersion correction, J. Comput. Chem. 27 (2006) 1787-1799, https://doi org/10.1002/jcc.20495.

[50] K. Lejaeghere, V. Van Speybroeck, G. Van Oost, S. Cottenier, Error estimates for solid-state density-functional theory predictions: an overview by means of the ground-state elemental crystals, Crit. Rev. Solid State Mater. Sci. 39 (2014) 1-24 https://doi.org/10.1080/10408436.2013.772503.

[51] C.J. Pickard, B. Winkler, R.K. Chen, M.C. Payne, M.H. Lee, J.S. Lin, J.A. White, V. Milman, D. Vanderbilt, Structural properties of Lanthanide and actinide compounds within the plane wave pseudopotential approach, Phys. Rev. Lett. 85 (2000) 5122-5125, https://doi.org/10.1103/PhysRevLett.85.5122.

[52] P. Hirunsit, T. Toyao, S.M.A.H. Siddiki, K. Shimizu, M. Ehara, Origin of Nb 205 lewis acid catalysis for activation of carboxylic acids in the presence of a hard base, ChemPhysChem. 19 (2018) 2848-2857, https://doi.org/10.1002/ cphc. 201800723.

[53] X. Ning, Y. Li, B. Dong, H. Wang, H. Yu, F. Peng, Y. Yang, Electron transfer dependent catalysis of Pt on N-doped carbon nanotubes: effects of synthesis method on metal-support interaction, J. Catal. 348 (2017) 100-109, https://doi. org/10.1016/j.jcat.2017.02.011.

[54] M. Pozzo, D. Alfè, Hydrogen dissociation and diffusion on transition metal ( $=\mathrm{Ti}$, Zr $\mathrm{V}, \mathrm{Fe}, \mathrm{Ru}, \mathrm{Co}, \mathrm{Rh}, \mathrm{Ni}, \mathrm{Pd}, \mathrm{Cu}, \mathrm{Ag})$-doped $\mathrm{Mg}(0001)$ surfaces, Int. J. Hydrogen Energy 34 (2009) 1922-1930, https://doi.org/10.1016/j.ijhydene.2008.11.109.
[55] M. Zhang, L. Chen, H. Yang, J. Ma, Theoretical study of acetic acid association based on hydrogen bonding mechanism, J. Phys. Chem. A 121 (2017) 4560-4568, https://doi.org/10.1021/acs.jpca.7b03324.

[56] S.F. Yuk, G. Collinge, M.-T. Nguyen, M.-S. Lee, V.-A. Glezakou, R. Rousseau, Selective acetylene hydrogenation over single metal atoms supported on Fe3O4 (001): a first-principle study, J. Chem. Phys. 152 (2020) 154703, https://doi.org/ 10.1063/1.5142748.

[57] Y.X. Li, M. Bowker, Acetic acid on Rh(110): the stabilization and autocatalytic decomposition of acetate, J. Catal. 142 (1993) 630-640, https://doi.org/10.1006/ jcat.1993.1236.

[58] X. Li, L. Xue, Y. Zhu, G. Chen, G. Yang, S. Wang, Mechanistic study of bio-oil catalytic steam reforming for hydrogen production: acetic acid decomposition, Int. J. Hydrogen Energy 43 (2018) 13212-13224, https://doi.org/10.1016/j. ijhydene.2018.05.066.

[59] B. Pekmezci Karaman, N. Cakiryilmaz, H. Arbag, N. Oktar, G. Dogu, T. Dogu, Performance comparison of mesoporous alumina supported $\mathrm{Cu} \& \mathrm{Ni}$ based catalysts in acetic acid reforming, Int. J. Hydrogen Energy 42 (2017) 26257-26269, https://doi.org/10.1016/j.ijhydene.2017.08.155.

[60] X. Li, Y. Zhu, G. Chen, G. Yang, Z. Wu, B. Sunden, Theoretical study of solvent effects on the decomposition of formic acid over a Co(111) surface, Int. J. Hydrogen Energy 42 (2017) 24726-24736, https://doi.org/10.1016/j. ijhydene.2017.08.022.

[61] X. Li, K. Xuan, Y. Zhu, G. Chen, G. Yang, A mechanistic study on the decomposition of a model bio-oil compound for hydrogen production over a stepped Ni surface: formic acid, Appl. Surf. Sci. 452 (2018) 87-95, https://doi.org/10.1016/j. apsusc.2018.05.049.

[62] F. Sanchez, D. Motta, A. Roldan, C. Hammond, A. Villa, N. Dimitratos, Hydrogen generation from additive-free formic acid decomposition under mild conditions by Pd/C: experimental and DFT studies, Top. Catal. 61 (2018) 254-266, https://doi. org/10.1007/s11244-018-0894-5.

[63] S. Ikeda, T. Nakajima, K. Hirao, A theoretical study of transition metal hydroxides: $\mathrm{CuOH}, \mathrm{AgOH}$ and AuOH, Mol. Phys. 101 (2003) 105-110, https://doi.org/ $10.1080 / 00268970210158696$. 